\title{
Consumidores plus size: uma proposta inclusiva para o Visual Merchandising
}

\section{Plus size consumers: a inclusive proposal for Visual Merchandising}

\author{
Vivian Andreatta $\operatorname{Los}^{[1]}$, Mariana Luísa Schaeffer \\ Brilhante $^{[2]}$, Emanoela Mardula ${ }^{[3]}$, Valdecir Babinski \\ Júnior $^{[4]}$, Camila Leithold ${ }^{[5]}$, Ezequiel Stack ${ }^{[6]}$, Lauane \\ Vanessa Wolffenbüttel ${ }^{[7]}$, Maria Augusta Zimmermann ${ }^{[8]}$
}

Resumo: por meio de uma pesquisa de campo embasada em uma revisão bibliográfica, o presente artigo propõe um modelo conceitual para adequação do Visual Merchandising (VM) no varejo de vestuário para o público plus size na cidade de Jaraguá do Sul (SC). Para esse fim, foram visitadas lojas de departamentos para recolher dados a respeito da organização de seus respectivos Pontos De Venda

[1] Mestra em Educação, FURB. vlos@ifsc.edu.br

[2] Mestranda em Design de Vestuário e Moda, UDESC. marsbxx@gmail.com

[3] Graduada em Design de Moda, UFSC. emanoela@ifsc.edu.br

[4] Mestre em Design de Vestuário e Moda, UDESC.vj.babinski@gmail.com

[5] Estudante do Curso Técnico Integrado em Modelagem do Vestuário, IFSC. camila.leitholdo9@gmail.com

[6] Estudante do Curso Técnico Integrado em Modelagem do Vestuário, IFSC. ezequielstack@gmail.com

[7] Estudante do Curso Técnico Integrado em Modelagem do Vestuário, IFSC.lauanelala83@gmail.com

[8] Estudante do Curso Técnico Integrado em Modelagem do Vestuário, IFSC. mariaaazimm2@gmail.com 
(PDV). Para a análise dos dados coletados foram estipuladas seis categorias: (I) gôndolas; (II) provadores; (III) cabides; (IV) placas de identificação (sinalização); (V) manequins; e (VI) oferta de tamanhos disponíveis. A partir dessa análise e da literatura investigada, elaborou-se um framework com os seguintes elementos de VM no PDV: (I) placas de identificação; (II) araras convencionais e araras para peças plus size; (III) mesas; (IV) manequins tradicionais e plus size; e (V) iluminação adequada. Como resultado, estima-se que o modelo possa contribuir para a inclusão dos consumidores plus size no varejo de vestuário usual.

Palavras-chaves:visual merchandising. Varejo devestuário. Consumidores plussize.

Abstract: through a field research based on a literature review, this article proposes a conceptual model for adapting Visual Merchandising (VM) in clothing retail for the plus size public in the city of Jaraguá do SuI (SC). To this end, department stores were visited to collect data about the organization of their respective Points Of Sale (POS). For the analysis of the collected data, six categories were stipulated: (I) gondolas; (II) fitting rooms; (III) hangers; (IV) identification plates (signage); (V) mannequins; and (VI) offer of available sizes. From this analysis and from the investigated literature, a framework was elaborated with the following VM elements at the POS: (I) nameplates; (II) conventional clothes rack and clothes rack for plus size pieces; (III) tables; (IV) traditional and plus size mannequins; and (V) adequate lighting. As a result, it is estimated that the model can contribute to the inclusion of plus size consumers in the usual clothing retail.

Keywords: visual merchandising. Clothing retail. Plus size consumers.

\section{INTRODUÇÃo}

De acordo com o Serviço Brasileiro de Apoio às Micro e Pequenas Empresas (SEBRAE, 2020), o Visual Merchandising (VM) consiste em uma estratégia de varejo que trabalha o ambiente do Ponto De Venda (PDV) para atrelar uma identidade de marca a uma determinada empresa. Nesses espaços, as técnicas de VM funcionam como uma ferramenta utilizada pelas organizações para compor a apresentação e a atmosfera no ambiente de comercialização de produtos. Nessas técnicas, considera-se a iluminação, as cores, o layout, o som, o aroma e a vitrine. O VM tem o intuito de melhorar e incentivar a experiência de compra e alavancar as vendas, uma vez que cerca de $70 \%$ das decisões de compra podem ser tomadas no PDV (NIELSEN, 2015).

Verifica-se que há um investimento por parte do varejo no VM para que o consumidor, além de adquirir o produto ou serviço que necessita, possa vivenciar uma experiência de compra agradável e que lhe proporcione emoções prazerosas, o que, por sua vez, configura-se em um elemento diferencial e decisi- 
vo no momento da compra (HERVÉ, 2009; PEDRON; STEFFEN; WOLF, 2014). Quanto à importância de adotar essas estratégias, Martins (2012) pontua que a prática do VM dá destaque às lojas e aos produtos pela maneira criativa de exibi-los. Para a autora, essas estratégias podem ser responsáveis por atrair a atenção dos clientes, aumentar a rotatividade dos produtos e, ainda, influenciar de maneira positiva o processo de decisão de compra.

De acordo com Assis (2011, p. 17), o comportamento do consumidor não se resume ao que acontece no instante em que um indivíduo entrega o dinheiro ao vendedor e, em troca, recebe uma mercadoria ou serviço: "[â€!] uma visão mais abrangente enfatiza esse processo incluindo as questões que os consumidores consideram antes, durante e depois da compra". Essas questões se baseiam na satisfação sentida no conjunto da experiência de compra. Moreno $(2012$, p. 8) destaca que "[â€!] as pessoas sentem desejos de consumo, independentemente de sua raça, religião ou tamanho do corpo".

Nessa perspectiva, Bard (2013) comenta que um público desassistido pelas estratégias de VM e que precisa ser incluso na experiência do PDV consiste nos consumidores plus size. Para a autora, a oferta de produtos de vestuário para esse público, geralmente, não acompanha as tendências de mercado ou de estilo, tampouco torna os espaços de comercialização confortáveis, física e psicologicamente, para esses indivíduos. Cabe destacar que esse grupo compreende um a cada quatro brasileiros acima de 18 anos, o que equivale a 41 milhões de pessoas (BRASIL, 2020).

Segundo a Associação Brasileira de Plus Size (ABPS, 2021), a indústria de vestuário teve queda de $5 \%$ nos últimos três anos. Contudo, o mercado de vestuário plus size cresceu $21 \%$ somente em 2018, o que levou o segmento a faturar cerca de $\mathrm{R} \$ 7,6$ bilhões naquele ano. Apesar do varejo tradicional ainda apresentar resistências a esses consumidores, os dados demonstram um crescimento de mercado expressivo. Para corroborar, Silva (2012) sublinha que varejistas mundiais, tais como 
Hennes \& Mauritz (H\&M), Zara (Inditex) e Forever 21, têm direcionado sua comunicação para esse público nos últimos anos.

Diante do exposto, o objetivo desse artigo encontra-se em propor um modelo conceitual para adequação do VM no varejo de vestuário para o público plus size na cidade de Jaraguá do Sul (SC). Como objetivos específicos, visa-se compreender de que maneira está organizado o PDV do varejo de vestuário local e identificar problemas passíveis de solução por intermédio de aporte teórico. Por fim, busca-se estabelecer um framework (modelo conceitual, em livre tradução) voltado ao atendimento ao público objetivado.

Justifica-se a proposição desse estudo a partir da problemática observada na forma como o VM está organizado perante o mercado plus size. Conforme versa a literatura, trata-se de um público que possui um desejo de compra que, por vezes, acaba sendo negligenciado pelo varejo. Segundo afirmam Scussel et al. (2018), de modo geral, as peças de vestuário plus size tendem a ser expostas em uma arara mais afastada com uma identificação chamativa para esses produtos, o que colabora para que o público-alvo se sinta diferente e estigmatizado.

Nesse sentido, estima-se que os resultados da pesquisa contribuam para a comunidade acadêmica e para futuros profissionais da área, a partir do descortinamento da problemática acerca do público plus size, vide seu potencial de consumo diante do varejo de vestuário. Espera-se, ainda, que empresas do setor possam apropriar-se dessa nova proposta de layout focado no atendimento às demandas dos consumidores plus size.

A metodologia deste trabalho tem como base a perspectiva de Gil (2008), e enquadra-se como uma pesquisa aplicada, qualitativa e descritiva. O corpo de conhecimento, apresentado a seguir, foi estruturado com base na literatura científica que versa sobre o VM no âmbito das empresas do vestuário, a exemplo de Cobra (2007), Blessa (2006), Demetresco (2007), Moreno (2012), Silva (2012), entre outros. 


\section{VISUAL MERCHANDISING NO VAREJO DE VESTUÁRIO}

Segundo Parente (2000), o varejo pode ser definido por um conjunto de atividades que englobam a comercialização de produtos e serviços com a finalidade de atender as necessidades do consumidor. O varejo do vestuário utiliza-se de alguns fatores controláveis com a intenção de influenciar o sentimento e o comportamento de compra dos consumidores a partir de promoções, preços e da estética do PDV. Cobra (2007) aponta que existem dois fatores fundamentais para estimular o consumidor à compra e obter uma otimização de vendas: o fator racional e o emocional.

Ao optar por utilizar a influência do fator emocional no momento da compra, faz-se possível atingir o objetivo da realização da compra por impulso (COBRA, 2007). Parente (2000) ressalta que uma atmosfera aconchegante e estimulante colabora diretamente nesse impulso e que esse estado de ativação pode ser fomentado pelos varejistas por meio de estratégias de VM. Acerca do termo VM, Morgan (2011) cita sua origem na década de 1980, como uma forma encontrada pelos lojistas em alternativa à promoção tradicional. Uma vez que o cenário da época era de uma recessão econômica global e havia a ameaça iminente do comércio eletrônico, os proprietários de lojas físicas se viram impelidos a criar estratégias criativas para atrair os clientes.

Blessa (2006), por sua vez, compreende que o VM como um conjunto de técnicas utilizadas no PDV para construir uma identidade intermediada por todos os elementos que contornam o produto. Nesse ambiente, o profissional de VM atua na área de trabalho proveniente do marketing que se dedica ao planejamento, ao desenvolvimento e à apresentação de diversos tipos e linhas de produtos aos públicos de um determinado negócio (SOUZA; FIGUEIREDO, 2018). Conforme Sackrider, Guidé e Hervé (2009), os componentes do VM contribuem para dar personalidade à empresa e constituir sua imagem. Por meio dele, transmite-se a impressão de loja que os varejistas desejam. 
Lemon e Verhoef (2016) acreditam que, nesse processo, os consumidores não almejam apenas o produto ideal, mas, principalmente, a experiência advinda da busca e da aquisição material. Segundo os autores, a experiência do consumidor pode ser categorizada em três estágios gerais: (I) a pré-compra, que tem início na necessidade ou no impulso de realizar a compra e engloba os aspectos de interação do consumidor com a marca e com a categoria e o ambiente antes da transação de compra; (II) a compra em si[9], relacionada a toda interação do consumidor com a marca e com o ambiente durante o evento de compra, o que inclui comportamentos de escolha, solicitação de produto ou serviço e pagamento; e (III) a pós-compra, que engloba a interação do consumidor com a marca e o seu ambiente na sequência da compra, o que perfaz comportamentos como o uso, o consumo, o envolvimento pós-vendas e os serviços requeridos.

Nos últimos anos, com o aumento do número de lojas parecidas e produtos cada vez menos diferentes, a experiência do consumidor passou a ser apontada, em diversos estudos, como uma forma de diferenciação cujo intuito está em cativar e manter clientes (ZORRILLA, 2002; VERHOEF et al., 2009; SHIN; PARK; MOON, 2015; LEMON; VERHOEF, 2016). Para criar essa diferenciação entre as lojas, utilizam-se recursos que vão desde layouts, cartelas de cores e aromas característicos, até técnicas de iluminação e formas de organização de expositores. Cobra (2007) acredita que essa comunicação espacial do PDV pode ser responsável pelo consumo de vestuário.

De modo similar, Parente (2000) defende que o layout interno e externo da loja tem importância na hora de reter consumidores. O layout externo sinaliza o tipo de atmosfera que os indivíduos encontrarão em seu interior, e o layout interno provoca o primeiro impacto nos consumidores, o que pode intervir diretamente na sua percepção sobre a qualidade dos produtos. O conjunto desses layouts, se articulado com as estratégias da empresa, pode acentuar a vantagem competitiva da organização sobre os concorrentes de mercado e criar uma posição de destaque na mente de seu público-alvo.
[9] Destaca-se que os autores desse artigo se dedicaram a pensar apenas o estágio da compra, pois nele reside a interação direta do público com o ponto de venda e as estratégias de VM. 
Parente (2000) acrescenta que o layout interno possui como principal objetivo proporcionar o fluxo suave de tráfego de consumidores dentro do ambiente e apresentar os produtos da melhor maneira possível. Segundo Cezar (2017), qualquer elemento que interfira na hora da locomoção dos indivíduos no PDV, como a estruturação das divisórias, pilares e provadores, pode prejudicar a venda dos produtos em oferta. Nessa mesma perspectiva, Cobra (2007) e Parente (2000) destacam que, no interior das lojas, o contato físico com os produtos e a facilidade de acesso podem ser relevantes para auxiliar na permanência dos consumidores no estabelecimento, o que, por sua vez, pode gerar mais estímulos ao consumo.

A largura da loja e o espaço dos provadores também influenciam no layout apropriado para que os indivíduos se sintam confortáveis e passem o maior tempo possível dentro da loja. Batista e Escobar (2020) ressaltam que esses aspectos podem estar associados com ao grau de conforto que a loja oferece aos consumidores. Isso implica dizer que, quando os corredores e provadores são mais largos, as pessoas se sentem mais à vontade para procurar e provar os produtos, enquanto em corredores e provadores estreitos os consumidores podem se sentir menos acolhidos devido ao constrangimento e a dificuldade em acessar os produtos da empresa.

Conforme exposto anteriormente por Cobra (2007), a cor, o aroma e a iluminação também possuem papéis significativos no VM da loja, pois, uma vez combinados, podem potencializar resultados durante a experiência de compra. Schmitt e Simonson (2000) defendem que esses elementos constituem o marketing sensorial que possui como objetivo agregar valor e diferenciação aos produtos ofertados com o apelo aos cinco sentidos (visão, audição, olfato, paladar e tato). Em especial, os autores advogam que a iluminação pode ser empregada para atrair e convidar consumidores para conhecer a loja de modo que, uma vez no interior do PDV, essa estratégia volta-se para o destaque aos produtos. Bigal (2001), Demetresco (2007) e Bailey e Baker (2014) confirmam o exposto por 
Schmitt e Simonson (2000) e acrescentam que a luz delimita a posição dos produtos e realça suas características materiais, tais como texturas, formas e cores.

Além da iluminação, Bailey e Baker (2014) mencionam que os expositores podem ser utilizados como equipamentos com a mesma função: expor os produtos e tornar a exibição mais dinâmica. Como aparatos para a exibição de produtos, os autores citam: araras, mesas, manequins, prateleiras, gôndolas e displays, entre outros. As mesas e os manequins podem ser compreendidos como expositores de uso tradicional no varejo de vestuário, visto que funcionam como ilhas criadas para que promoções fiquem mais visíveis para os consumidores que se locomovem pela loja. Demetresco (2007) orienta que os manequins devem representar o modelo ideal de uma figura humana e devem ter como função a identificação dos consumidores com o estilo de vestuário proposto pela empresa, de forma que esses venham a se reconhecer naqueles produtos.

Do ponto de vista dos displays presentes no PDV, Blessa (2003) afirma que a maneira como os produtos estão expostos influencia no momento de decisão de compra dos consumidores e que, portanto, os displays podem ser utilizados para apresentar informações de modo visual. Segundo a autora, esses aparatos complementam a sinalização do ambiente e servem como instrumento para persuadir os consumidores, além de funcionarem como mobiliário ao espaço da loja.

Assim, para Blessa (2003), os varejistas que estiverem atentos a disposição de displays no PDV de seus negócios podem alcançar maior sucesso comercial que aqueles que não empregam técnicas de VM. Cobra (2007) confirma o exposto e adiciona que é preciso articular a relação dos consumidores com os espaços físicos nos quais o consumo pode ser exercido, de modo a potencializar a decisão de compra. Uma vez explorada a fundamentação teórica desse artigo, no próximo tópico, apresentam-se os procedimentos metodológicos usados na presente pesquisa. 


\section{PROCEDIMENTOS METODOLÓGICOS}

$\mathrm{Na}$ presente pesquisa, o corpo de conhecimento da fundamentação teórica foi construído randomicamente por meio de uma revisão bibliográfica assistemática e narrativa. As informações coletadas foram tratadas de modo qualitativo e com base em uma postura epistemológica interpretativista. Para amostragem da pesquisa, estipulou-se como critério de seleção: (I) a proximidade física com a unidade central do câmpus de Jaraguá do Sul do Instituto Federal de Santa Catarina (IFSC/ JAR), onde estudam e lecionam os autores; e (II) a configuração do estabelecimento enquanto loja de departamentos. Portanto, selecionaram-se para o recorte: (I) Havan; (II) Riachuelo; (III) Renner; (IV) Pernambucanas; e (V) Lojas Americanas ${ }^{[0]}$.

Para a etapa de campo da pesquisa, empregaram-se: (I) uma observação não-participante com visitação in loco no varejo local; e (II) um diário fotográfico dos PDV. O período de observação compreendeu o espaço de 30 de junho de 2021 até 07 de junho do mesmo ano. Nas lojas, foram verificados: (I) displays; (II) gôndolas; (III) manequins; (IV) vitrines; (V) provadores; e (VI) corredores. Apesar da literatura indicar cores, aromas e formas de iluminação como técnicas de VM, esses aspectos não foram considerados pelos autores diante da ausência de tempo hábil para a prática da observação.

Ademais, para a elaboração do modelo conceitual de VM, seguiu-se as seguintes etapas: (I) análise do que a fundamentação propõe como ideal de VM; (II) contraposição aos dados coletados na pesquisa de campo; (III) planejamento do layout de um VM adequado ao espaço interno em lojas de departamento; e (IV) execução do protótipo. Importa comentar que, concluída a pesquisa bibliográfica sobre a definição de VM e de seus elementos constituintes, a etapa de campo obteve os dados presentes no Quadro 1 a partir da verificação in loco.
[10] Doravante, para evitar quaisquer constrangimentos ou prejuízos à imagem pública dos estabelecimentos observados, utilizar-se-á a denominação Loja I, Loja II, Loja III, Loja IV e Loja V. 
Quadro 1 - Dados obtidos na observação não-participante do visual merchandising

\begin{tabular}{|c|c|c|c|c|}
\hline $\begin{array}{l}\text { Dia da } \\
\text { visitação }\end{array}$ & $\begin{array}{l}\text { Local } \\
\text { visitado }\end{array}$ & $\begin{array}{l}\text { Tempo de } \\
\text { visitação }\end{array}$ & Aspectos analisados & $\begin{array}{l}\text { Registros } \\
\text { fotográficos }\end{array}$ \\
\hline 30/06/2021 & Loja I & 10 minutos & $\begin{array}{l}\text { - Quatro gôndolas de roupas } \\
\text { plus size disponíveis; } \\
\text { - cabide padrão para todos os tamanhos; } \\
\text { · placas de sinalização pequenas; } \\
\text { - não se obteve acesso aos provadores. }\end{array}$ & $\begin{array}{l}\text { Quatro } \\
\text { fotografias }\end{array}$ \\
\hline $30 / 06 / 2021$ & Loja II & 15 minutos & $\begin{array}{l}\text { - Quatro gôndolas; } \\
\text { - tamanhos disponíveis do GG ao XGG; } \\
\text { - peças plus sizes mal distribuídas } \\
\text { em cabides pequenos; } \\
\text { - cinco provadores pequenos. }\end{array}$ & $\begin{array}{l}\text { Nove } \\
\text { fotografias }\end{array}$ \\
\hline $30 / 06 / 2021$ & Loja III & 10 minutos & $\begin{array}{l}\text { - Sem gôndolas; } \\
\text { - tamanhos disponíveis até o } 48 \text {; } \\
\text { - venda de vestuário plus size apenas } \\
\text { online pela marca própria; } \\
\text { - peças plus size apenas disponíveis } \\
\text { em lojas de capitais. }\end{array}$ & $\begin{array}{l}\text { Três } \\
\text { fotografias }\end{array}$ \\
\hline 0707/2021 & Loja IV & 20 minutos & $\begin{array}{l}\text { - Apresenta seis gôndolas de vestuário } \\
\text { plus size, com tamanhos do } 48 \text { ao } 52 ; \\
\text { - sem cabides apropriados para peças } \\
\text { plus size, e pouco organizados; } \\
\text { - placas de sinalização bem } \\
\text { visíveis, logo na entrada; } \\
\text { - sem manequins plus size; } \\
\text { - sem peças plus size nas vitrines; } \\
\text { - provadores adequados. }\end{array}$ & $\begin{array}{l}\text { Cinco } \\
\text { fotografias }\end{array}$ \\
\hline 07/07/2021 & Loja V & 10 minutos & $\begin{array}{l}\text { - Não foram encontradas peças } \\
\text { de vestuário plus size; } \\
\text { - não tem cabides apropriados para } \\
\text { as demais peças de vestuário; } \\
\text { - provadores adequados. }\end{array}$ & $\begin{array}{l}\text { Uma } \\
\text { fotografia }\end{array}$ \\
\hline
\end{tabular}

Fonte: elaborado pelos autores (2021). 
Conforme pode-se observar no Quadro 1, há realidades distintas em cada um dos PDV visitados. As observações realizadas nesses espaços foram contrapostas com a literatura investigada e foram organizadas a partir de seis categorias de sumarização: (I) gôndolas; (II) provadores; (III) cabides; (IV) placas de identificação (sinalização); (V) manequins; e (VI) oferta de tamanhos. Assim, a seguir, apresenta-se a discussão das categorias.

\subsection{PRIMEIRA CATEGORIA: GÔNDOLAS}

Avaliou-se a existência de gôndolas em cada uma das lojas visitadas e a quantidade de expositores que essas possuíam. Observou-se que: duas (40\%) das lojas visitadas apresentavam de uma a três gôndolas destinadas às peças de vestuário em tamanhos plus size em seu PDV; (II) duas lojas (40\%) analisadas não disponibilizavam gôndolas para o vestuário plus size em seus ambientes físicos; e (III) a loja IV (o que representa $20 \%$ ) oferece de três a seis gôndolas com esta finalidade.

Os dados observados vão ao encontro do exposto por Bard (2013), que acredita que a oferta de produtos de vestuário para o público plus size não é adequada ao volume de pessoas que buscam esses produtos. Para a autora, a proposta estabelecida pelo varejo tradicional está aquém das necessidades e expectativas do público em questão, o que pode ser confirmado ao se constatar que, na maioria das lojas investigadas, a quantidade de gôndolas ocupadas por peças destinadas a esse público é pequena. Entende-se que a existência de mais expositores de peças plus size, bem como a própria oferta física de produtos do segmento nas lojas físicas, pode favorecer a valorização e a inclusão desses consumidores no varejo, além de prover incremento às vendas dos lojistas.

\subsection{SEGUNDA CATEGORIA: PROVADORES}

Outro fator analisado foi a configuração dos provadores com relação à sua configuração espacial. Percebeu-se que das cinco lojas visitadas, quatro possuem provadores confortáveis em questão de dimensionamento, entretanto, essas lo- 
jas não apresentam adaptações para atender ao público plus size, tais como cabines espaçosas ou mobiliário próprio para pessoas com morbidades severas que encontram barreiras em vestir e despir as peças.

De acordo com Sant'Anna (2013), os provadores para plus size devem ser maiores do que os convencionais e disporem de banquetas confortáveis. Diferentemente do que orienta a autora, constatou-se que uma das lojas oferece, inclusive, provadores menores que o tradicional[11], com dimensões que prejudicam a movimentação dos consumidores e a visualização da peça. Além disso, percebeu-se que poucas foram as lojas que enfatizaram a iluminação, a climatização e o espelho no local, o que, acredita-se, de outro modo, poderia auxiliar os indivíduos na hora da decisão de compra.

\subsection{TERCEIRA CATEGORIA: CABIDES}

Quanto aos cabides próprios para peças plus size, observou-se que $80 \%$ das lojas visitadas apostavam no uso indiscriminado de cabides do tamanho 34 ao 44, ou seja, que não estavam adequados para peças maiores. Percebeu-se que das cinco lojas visitadas, todas usavam o mesmo padrão de cabides para peças do vestuário, o que gerava a impressão de roupas mal acomodadas. Além de amarrotar e danificar os tecidos, esse aspecto dificulta a visualização das peças e, muitas vezes, desmotiva os consumidores a experimentá-las, conforme expõe Blessa (2003).

Em contraposição com o exposto por Blessa (2003) que afirma que a maneira como os produtos estão ofertados nos dispositivos de alcance dos consumidores influencia no quanto eles podem ser acessados e, portanto, adquiridos -, os dados indicam que os lojistas pesquisados não acreditam no potencial de vendas das peças de vestuário plus size, uma vez que, mal acondicionadas, essas peças servem como desincentivo ao público em questão.
[11] Se comparado com os espaços de provadores das outras lojas observadas na pesquisa. 


\subsection{QUARTA CATEGORIA: PLACAS DE IDENTIFICAÇÃO (SINALIZAÇÃO)}

Essa categoria se refere ao modo como foi sinalizada a oferta de produtos para o público plus size nas lojas. As placas de identificação indicam a localização de peças em tamanhos maiores dentre as demais numerações, de forma a facilitar o acesso do cliente e, assim, contribuir para a venda dos produtos. Ressalta-se que foi possível fazer esta averiguação em apenas três das cinco lojas visitadas, afinal, duas delas não trabalham com tamanhos plus size (o que representa $40 \%$ da amostra). Constatou-se que apenas $60 \%$ das lojas apresentavam identificação clara e objetiva desses produtos, porém, em uma delas, a sinalização era menos evidente do que nas demais.

Para Blessa (2003), as placas de identificação e displays auxiliam no processo de venda ao informar os consumidores a respeito da oferta de produtos para o seu perfil. Essas placas de identificação orientam os indivíduos na busca por peças adequadas e direcionam seu percurso no PDV, além de auxiliar no processo de divulgação. Pelo observado, os lojistas que optam por atuar no segmento plus size possuem estratégias de sinalização sobre a oferta dessas peças em seus estabelecimentos, o que, acredita-se, contribui positivamente para o consumo das mesmas.

\subsection{QUINTA CATEGORIA: MANEQUINS}

Nessa categoria, buscou-se avaliar a disposição das peças de vestuário em suportes que representem, de forma realista, o formato do corpo a quem as peças se destinam, seja na vitrine ou no interior das lojas. Constatou-se que em apenas uma das lojas analisadas (20\%) havia manequins com tamanho plus size e que, em quatro lojas (80\%), não havia manequins correspondente às dimensões corporais do público envolvido.

Para Demetresco (2007), o uso de manequins como parte das técnicas de VM pode potencializar a decisão de compra se esses dispositivos apresentarem dimensões semelhantes 
com a figura humana do público-alvo objetivado pela empresa. Nesse sentido, os manequins funcionam como aparatos para sensibilizar os consumidores e motivá-los a provar as peças, uma vez que criam um pareamento entre objetos e pessoas. Todavia, os dados coletados demonstram que apenas uma loja possui manequins plus size, o que a coloca à frente das demais no atendimento a esses consumidores.

\subsection{SEXTA CATEGORIA: OFERTA DE TAMANHOS}

Diante dessa categoria, constatou-se que duas lojas atendem ao público plus size ao ofertar peças de vestuário em numerações que vão do 48 ao 52, o que representa 40\% da amostra. Verificou-se, também, que uma das lojas ofertava peças acima do número 52. Por fim, observou-se que: (I) uma das lojas pesquisadas não ofertava peças de vestuário para o público plus size em seu ambiente físico, mas dispunha da opção de compra pelo comércio eletrônico; e (II) outra das lojas não possuía peças de vestuário plus size no ambiente de PDV e, tampouco, em seu website.

Em consonância à literatura pesquisada e, em especial, com os dados da ABPS referentes ao crescimento do segmento, pode-se compreender que houve uma valorização na oferta de peças do vestuário para o público plus size, haja vista que, das cinco lojas, quatro delas possuíam grades de numeração para atender esses consumidores, ainda que por meio do comércio eletrônico e mesmo que a diversidade de modelos não fosse expressiva. Assim, descritas as categorias de sumarização e os dados encontrados, procede-se para a descrição do modelo conceitual.

\section{MODELO CONCEITUAL DE VM PARA O VAREJO DE VESTUÁRIO}

A formatação da proposta do modelo conceitual de VM para o varejo de vestuário plus size baseou-se no que foi verificado na pesquisa de campo e levou em consideração as informações encontradas na literatura investigada. Em um primeiro 
momento, elencou-se os elementos prioritários na configuração de um PDV ideal perante a concepção abordada e, a seguir, desenhou-se um esboço manual. Após isso, foi realizada a transferência desta proposta manual para o computador

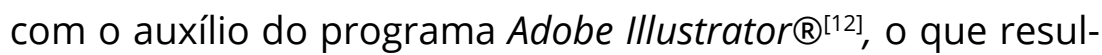
tou na representação gráfica do framework (Figura 1).

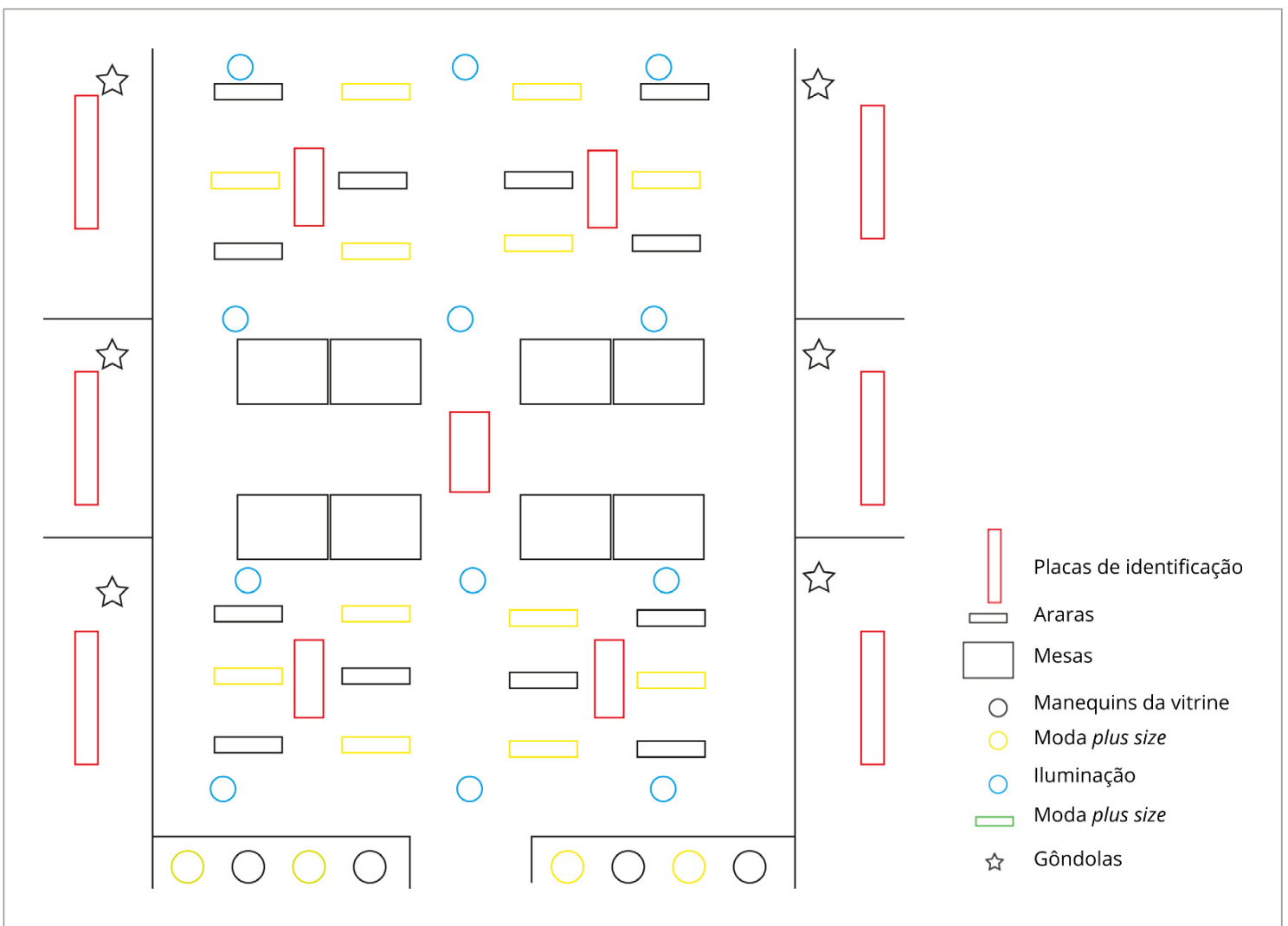

[12] O programa foi escolhido por sua capacidade de construção de recursos gráficos e pela familiaridade dos autores com a interface do software.

Figura 1 - Proposta de modelo conceitual de VM para o varejo do vestuário plus size Fonte: elaborada pelos autores (2021).

A proposta de VM (Figura 1) foi pensada pelos autores a fim de proporcionar uma experiência confortável para os consumidores plus size e potencializar a possibilidade de efetivação da compra. Nesse sentido, foram considerados os seguintes elementos: (I) placas de identificação; (II) araras convencionais e araras para peças plus size; (III) mesas; (IV) manequins tradicionais e plus size; e (V) iluminação adequada. Orienta-se que a pre- 
sença de manequins plus size deve, preferencialmente, atender a uma diversidade de corpos, gêneros e raças. Da mesma maneira, a oferta de peças de vestuário para esses consumidores também deve apresentar determinada pluralidade de modelos.

No framework supramencionado (Figura 1), as araras podem ser compreendidas como gôndolas e, tal como as mesas, podem ser utilizadas com a presença de displays e outros aparatos promocionais. Nesse cenário, além de sinalizar informações importantes, as placas de identificação também podem ser usadas para atrair os consumidores que transitam no interior da loja para nichos ou ilhas de produtos específicos. A disposição desses elementos no PDV corrobora com o exposto por Parente (2000) e Cobra (2007) ao passo em que, pela presença dos manequins plus size na vitrine, também confirma a observação de Blessa (2003) que acredita que, para um produto ser lembrado e desejado, ele precisa ser visto e exposto.

Com base na literatura, estima-se que esses manequins possam apresentar certo grau de familiaridade com os consumidores plus size, o que, em tese, permite a visualização das peças e de detalhes materiais importantes para efetivar a compra, tais como o volume, o caimento e comportamento dos tecidos e das malhas em relação ao corpo. Além da presença desse elemento, para gerar um estado de conforto e de relaxamento que possa facilitar a compra e gerar prazer com essa experiência, o framework propõe que o espaço destinado à circulação entre os aparatos do PDV seja respeitado e espaçoso o suficiente para que consumidores plus size possam locomover-se sem ter de enfrentar barreiras ou empecilhos.

Conforme visto na fundamentação teórica desse artigo, se o fluxo do tráfego interno da loja for otimizado e oportunizar um passeio agradável entre os produtos, principalmente na dinâmica de acesso aos corredores e às ilhas de oferta, há mais chances de a compra ser efetivada. Isso posto, no framework, os corredores de circulação foram integrados com araras de vestuário plus size espalhadas pela loja para causar a impressão de uma ampla gama de produtos e para supe- 
rar o estigma dos nichos escondidos ou isolados nas lojas de departamento, tal como foi observado por Scussel (2018). A autora indica que se faz necessário pensar em estratégias para compor o PDV de modo a não gerar uma área específica de produtos plus size preterida do restante do ambiente de comercialização das peças, pois, uma vez que isso ocorra, pode-se gerar mais exclusão do que inclusão.

Nesse percurso, sugere-se que as araras sejam organizadas por modelos e dispostas na grade correspondente, desde o menor até o maior tamanho disponível na loja. Ademais, a projeção do modelo conceitual dedica-se, ainda, a pensar outro fator de VM: a iluminação. Por intermédio do framework gerado, os autores propõem que a iluminação seja regular e bem distribuída para tornar o ambiente convidativo e visualmente confortável. Pontos focais podem ser adicionados para destacar produtos em promoção e na vitrine da loja para acentuar as características materiais dos modelos em exibição.

Por fim, importa comentar que o modelo conceitual elaborado não apresenta diretrizes para os provadores. No entanto, os autores endossam a literatura que orienta para que esses espaços devam ser amplos o suficiente para não gerar desconforto na hora de vestir ou despir uma peça de vestuário. Se possível, a loja deve dispor de mobiliário específico nos provadores para auxiliar os consumidores plus size (com e sem necessidades específicas) nessa situação, tais como corrimãos, cadeiras, mesas e cabides adaptados. Com isso, acredita-se que o VM possa ser utilizado, estrategicamente, para gerar mais inclusão no PDV do que o observado, atualmente. Apresentado o framework, procede-se para as considerações finais.

\section{CONSIDERAÇÕES FINAIS}

No presente artigo, compreendeu-se a relevância de estudos voltados às estratégias de VM para a inclusão dos consumidores plus size no varejo convencional. Com isso, enfatizou-se a importância da adoção de técnicas de VM com o intuito de atender adequadamente o segmento em questão, no am- 
biente do PDV e de forma a proporcionar uma experiência de compra satisfatória. De acordo com a literatura consultada, foi verificado que as técnicas de VM podem influenciar no processo de decisão de compra e que as diversas possibilidades na configuração do espaço de vendas podem privilegiar a apresentação de certos produtos em detrimento de outros, o que pode atingir o consumidor e impactar em suas escolhas.

Diante desse cenário, o objetivo desse artigo foi propor um modelo conceitual para adequação do VM no varejo de vestuário para o público plus size na cidade de Jaraguá do Sul (SC). Inicialmente, empreendeu-se uma pesquisa bibliográfica para conceituar o VM e identificar as principais técnicas que o compõem. Em seguida, foi realizada uma pesquisa de campo, com o intuito de compreender de que maneira estava organizado o PDV do varejo de vestuário local e identificar problemas passíveis de solução por intermédio de aporte teórico.

Nessa etapa, os autores dirigiram-se a lojas de departamento de Jaraguá do Sul (SC), com o intuito de analisar o ambiente do PDV e identificar sua configuração em relação à disposição dos produtos ofertados ao segmento plus size. Dentre os resultados obtidos nessas visitas, destaca-se que, das cinco lojas analisadas, apenas três disponibilizavam peças em tamanhos grandes. Das duas que não ofereciam esse segmento em loja, uma não possuía uma grade de tamanhos apropriada ao público estudado, e a outra só disponibilizava peças plus size em lojas físicas situadas em capitais ou por meio de comércio eletrônico.

Mesmo as lojas visitadas que possuíam peças plus size apresentavam outros empecilhos, como o dimensionamento de corredores, o espaço de provadores e a diversidade de modelos ofertados. Assim, a partir do observado em campo, se extrapolados cenários, pode-se constatar que os consumidores plus size estão, em geral, desassistidos e excluídos do varejo tradicional se distantes de grandes centros urbanos. Outra constatação que se destaca reside no fato de que apenas uma das lojas apresentava placas que sinalizavam, de forma adequada, a localização das peças de tamanhos maio- 
res. Essa mesma loja também tinha expositores que acomodavam as peças plus size satisfatoriamente, diferente do percebido nas demais lojas visitadas. Estima-se que a falta de organização em relação à sinalização, aos displays e aos expositores pode dificultar o processo de compra dos consumidores e pode prejudicar a atmosfera pretendida pelo varejista.

$\mathrm{Na}$ última parte da pesquisa, buscou-se estabelecer um framework voltado para o atendimento ao público objetivado. A construção desse modelo conceitual foi subsidiada pela problemática verificada in loco e pelos pressupostos teóricos investigados. O resultado foi uma proposta que contempla os seguintes elementos de VM no PDV: (I) placas de identificação; (II) araras convencionais e araras para peças plus size; (III) mesas; (IV) manequins tradicionais e plus size; e (V) iluminação adequada. Embora a intenção da proposta estivesse em prover uma experiência de compra agradável e confortável para os consumidores plus size de modo a incluí-los no varejo tradicional, reconhece-se que o modelo é passível de melhorias.

Por fim, conclui-se que o público ao qual essa pesquisa se dedicou pode se deparar com uma série de empecilhos, na hora da compra, que o excluem do varejo de vestuário convencional, tais como a falta de representatividade de seus corpos nos manequins dispostos no PDV, a desorganização na disposição das peças ofertadas ou a presença de sinalizações insuficientes, dentre outros entraves. Assim, para se alcançar um estado de inclusão dos consumidores plus size na dimensão do comércio físico, o VM deve estar orientado para a supressão desses empecilhos e para a criação de um ambiente aconchegante, acoIhedor e seguro para que esses indivíduos exerçam o consumo. 


\section{REFERÊNCIAS}

\section{ABPS. Relatório setorial mercado plus size no Brasil,}

2021. Disponível em: https://www.plussizebrasil.com.br/ relatorio21mercadoplusize. Acesso em: 4 abr. 2021.

ASSIS, F. Comportamento do consumidor. 2011.

Monografia apresentada ao MBA. Gestão e

Estratégia Empresarial da UNIFIL Centro Universitário

Filadélfia. Londrina, 2011. Disponível em: https://

web.unifil.br/pergamum/vinculos/000004/0000043D.

pdf. Acesso em: 25 maio 2021.

\section{BAILEY, S.; BAKER, J. Moda e visual merchandising.}

1. ed. São Paulo: Gustavo Gili, 2014.

BARD, N. L. S. A moda como representação de identidade em consumidoras plus size. 2013. PG. Trabalho de Conclusão de Curso - Universidade Federal do Rio Grande do Sul, Porto Alegre, 2013. Disponível em: https://lume. ufrgs.br/handle/10183/88875. Acesso em: 1 fev. 2021.

BATISTA, K.; ESCOBAR, M. A. R. A importância do visual merchandising na percepção dos consumidores. R. Gest. Anál., Fortaleza, v. 9, n. 1, p. 93-108, jan./abr. 2020.

Disponível em: https://periodicos.unichristus.edu.br/gestao/ article/viewFile/2567/1059. Acesso em: 4 ago. 2021.

BIGAL, S. Vitrina: do outro lado do visível. São Paulo, SP: Nobel, 2001.

BLESSA, R. Merchandising no ponto-de-

venda. 2. ed. São Paulo, SP: Atlas, 2003.

BRASIL. Pesquisa do IBGE mostra aumento da obesidade entre adultos. 2020. Disponível em:

https://www.gov.br/pt-br/noticias/saude-e-vigilanciasanitaria/2020/10/pesquisa-do-ibge-mostra-aumentoda-obesidade-entre-adultos. Acesso em: 28 fev. 2021. 
CEZAR, J. G. Visual merchandising no varejo de moda: importância e aplicabilidade. Monografia (Curso de Comunicação Social - Publicidade e Propaganda) Universidade do Sul de Santa Catarina, 2017. Disponível em: https://repositorio.animaeducacao.com.br/bitstream/ ANIMA/10503/1/Monografia\%20-\%20Jhenefer\%20 Garcia\%20Cezar.pdf. Acesso em: 9 ago. 2021.

COBRA, M. Marketing \& moda. São Paulo:

Editora SENAC São Paulo, 2007. 263 p.

DEMETRESCO, S. Vitrina: construção de encenações. 3. ed. São Paulo: Editora SENAC São Paulo, 2007. 264 p.

GIL, A. C. Métodos de pesquisa social.

6. ed. São Paulo: Atlas, 2008.

LEMON, K. N.; VERHOEF, P. C. Understanding customer experience throughout the customer journey. Journal of Marketing, [S.I.], v. 80, n. 6, p. 69-96, nov. 2016.

MARTINS, F. Z. A influência do visual merchandising no comportamento de compra do consumidor. Monografia de Conclusão do Curso (Comunicação Social) - Centro Universitário de Brasília, 2012. 47 f. Disponível em: https://repositorio.uniceub.br/ jspui/bitstream/123456789/2045/2/20861488. pdf. Acesso em: 10 nov. 2021.

MORENO, T. V. A. Constituição dos sentidos da mulher "plus size". Revista Avepalavra, Alto Araguaia, v., n. 14, nov./dez. 2012. Disponível em: http://www2.unemat.br/avepalavra/ EDICOES/14/artigos/MORENO.pdf. Acesso em: 29 jan. 2021.

MORGAN, T. Visual merchandising: vitrines e interiores comerciais. 2. ed. Barcelona: Editora GG, 2011.

NIELSEN. A hora certa de ativar o shopper. [S.I.:

s.n.], 2015. Disponível em: https://www.nielsen.com/ wp-content/uploads/sites/3/2019/04/NielsenSeriesShopper-2015.pdf. Acesso em: 8 mar. 2021. 
PARENTE, J. Varejo no Brasil: gestão e

estratégia. São Paulo: Atlas. 2000. 388 p.

PEDRON, R.; STEFFEN, C.; WOLF, F. O design no

comportamento do consumo: o ambiente de varejo

e a decisão de compra, 2014. Anaisâ€! X semana de

extensão, pesquisa e pós-educação - SESpesq, centro

universitário ritter dos reis. Disponível em: http://www.

uniritter.edu.br/uploads/eventos/sepesq/x_sepesq/arquivos_

trabalhos/2968/368/371.pdf. Acesso em: 14 jun. 2021.

SACKRIDER, F.; GUIDÉ, G.; HERVÉ, D. Entre vitrinas:

distribuição e visual merchandising na moda.

São Paulo: Editora Senac São Paulo, 2009.

SANT'ANNA, M. C. dos P. Uma abordagem para

a moda plus size no mercado de luxo. 2013.

Disponível em: https://ied.edu.br/biblioteca/sao-

paulo/01_01_13278.pdf. Acesso em: 24 jul. 2021.

SCHMITT, B. H.; SIMONSON, A. A estética do

marketing: como criar e administrar sua marca, sua imagem e identidade. São Paulo: Nobel, 2000.

SCUSSEL, F. B. C. et al. Muito além das curvas: a experiência de consumo das mulheres brasileiras plus size no varejo de moda. Alcance, Itajaí, v. 25, n. 1, p. 79-94, jan./abr. 2018.

SEBRAE. Visual merchandising. 2020. Disponível em: https://www.sebrae.com.br/sites/PortalSebrae/ufs/ap/ artigos/visual-merchandising,b9d3ace85e4ef510VgnV CM1000004c00210aRCRD. Acesso em: 7 mar. 2021.

SHIN, J. K.; PARK, M. S.; MOON, M. K. Do Eco friendly VMD and Store Reputation Increase Satisfaction of Retail Customers? Psychology \& Marketing, v. 32, n. 12, p. 1148-1157, 2015. 
SILVA, N. M. O Consumidor Plus Size Como um Novo

Padrão Estético na Moda Contemporânea. São Paulo, 2012. 62 p. Monografia (Curso de Especialização em

Estética e Gestão de Moda) - Universidade de São Paulo.

Disponível em: http://www2.eca.usp.br/moda/monografias/

Natalia\%20Magalhaes.pdf. Acesso em: 1 fev. 2021.

SOUZA, C. da L.; FIGUEIREDO, G. L. A. de S. O profissional

de visual merchandising e o desafio de encantar

clientes através da comunicação. Disponível em:

https://jnt1.websiteseguro.com/index.php/JNT/article/

download/263/260. Acesso em: 5 maio 2021.

VERHOEF, P. C. et al. Customer experience creation:

Determinants, dynamics and management strategies.

Journal of retailing, v. 85, n. 1, p. 31-41, 2009.

ZORRILLA, P. Nuevas tendencias en merchandising:

Generar experiencias para conquistar emociones y fidelizar

clientes. Distribución y Consumo, n. 65, p. 13-20, 2002. 